\title{
Regulation of Fructose Uptake by Glucose in Escherichia coli
}

\author{
By DÉA AMARAL* AND H. L. KORNBERG† \\ Department of Biochemistry, School of Biological Sciences, \\ University of Leicester, Leicester $L_{\mathrm{I}}{ }_{7} R H$
}

(Received 8 April 1975)

\begin{abstract}
SUMMARY
A mutant, DAI, has been isolated from the Escherichia coli KI2, strain K2.It, as a colony resistant to 2-deoxyglucose (DG) when growing on fructose but still sensitive to DG when growing on other sugars. The mutation in DAI specifically affects the catabolite inhibition of fructose utilization by glucose and glucose-6-phosphate; the affected gene (designated cif) is located at min 4I on the E. coli linkage map and is highly co-transducible with the genes that specify the uptake of fructose $(p t s F)$ and enzymic conversion of fructose-I-phosphate to fructose-I,6-bisphosphate $(f p k)$.
\end{abstract}

\section{INTRODUCTION}

The addition of glucose to cultures of Escherichia coli grówing on a wide variety of other carbon sources rapidly inhibits the utilization of those substrates. This phenomenon, which has been termed 'catabolite inhibition' by McGinnis \& Paigen (1969, 1973), is due to interference by glucose with the continued uptake of the other substrates. Noncatabolizable analogues of glucose, such as methyl- $\alpha$-D-glucoside, and I- and 2-deoxy-Dglucose, were found to exert a similar inhibitory effect on carbohydrate transport, but only if the organisms had been previously induced for the uptake of such analogues (Kepes, 1960; Kessler \& Rickenberg, 1963; Koch, 1964; Boniface \& Koch, 1967; Winkler $\&$ Wilson, 1967). This suggests that it is either the actual process of translocation of glucose and its analogues into the cells, or elevation of the intracellular concentration of the 6-phosphate esters formed from these materials, that inhibits the uptake of other substrates. In accordance with either explanation, it has been found that, in mutants impaired in glucose-specific components of the phosphotransferase (PT) system (Kundig, Ghosh \& Roseman, 1964), glucose and its non-catabolizable analogues do not inhibit the uptake of substances such as galactose (Asensio, Avigad \& Horecker, 1963; Kornberg, 1973 $a$ ) and fructose (Kornberg, 1972, 1973a).

This paper describes the properties of a mutant of $E$. coli in which specifically the uptake of fructose is much less inhibited by glucose and by its non-catabolizable analogues than it is in the parent organism. The utilization of fructose by the mutant is also less susceptible to inhibition by glucose-6-phosphate. The gene that specifies this altered behaviour is highly co-transducible with those specifying fructose-I-phosphate kinase $(f p k)$ and a fructose-specific component of the multicomponent PT-system (ptsF) (JonesMortimer \& Kornberg, 1974). These findings suggest that, in E. coli, glucose exerts not only a pleiotropic inhibition on the uptake of many carbohydrates, which is associated with the uptake and phosphorylation of glucose via the PT-system, but can also inhibit

* Present address: Departamento de Bioquimica, Universidade Federal do Paraná, P.O. Box 939, Curitiba, Brazil.

$\dagger$ Present address: Department of Biochemistry, University of Cambridge, Tennis Court Road, Cambridge CB2 IQW. 
Table I. Strains of E. coli KI2 used

\begin{tabular}{|c|c|c|c|}
\hline Organism & Genetic markers & Mating type & Reference or source \\
\hline AT2243 & metB ura & Hfr-C & Gift from A. L. Taylor \\
\hline AT2243. II ${ }^{\mathrm{c}}$ & metB ura uhp ${ }^{\mathrm{c}}$ & Hfr-C & Ferenci \& Kornberg (1973) \\
\hline AT2243. II $^{\mathrm{c}} .25$ & metB ura uhpc fpk & Hfr-C & Ferenci \& Kornberg (1973) \\
\hline KLI 6 & - & Hfr & Gift from B. Low \\
\hline KLI6.2I & $p t s F p t s X$ & Hfr & Ferenci \& Kornberg (197I) \\
\hline KLI 6.25 & $f p k$ & Hfr & Gift from M. C. Jones-Mortimer \\
\hline KLI 6.30 & cif & Hfr & This paper \\
\hline K2.It & his argH thr leu pps str & $\mathrm{F}^{-}$ & Brice \& Kornberg (1967) \\
\hline K2.It. $\theta$ & his argH thr leu pps thyA str & $\mathrm{F}^{-}$ & Trimethoprim $^{\mathrm{R}}$ derivative of $\mathrm{K2.I}$ \\
\hline DAI & his argH thr leu pps cif str & $\mathrm{F}^{-}$ & This paper \\
\hline DA3 & metB ura uhp cif & Hfr-C & This paper \\
\hline DA6 & his ura cif str & $\mathbf{F}^{-}$ & This paper \\
\hline $\mathrm{K} 2 . \mathrm{I} .22$ & his argH thr leu pps umg str & $\mathbf{F}^{-}$ & Kornberg \& Smith (I972) \\
\hline $\mathrm{K} 2.22 .25$ & argH thr leu fpk umg str & $\mathbf{F}^{-}$ & [AT2243.1 I $\left.{ }^{\mathrm{C}} .25 \times \mathrm{K2} .1 .22\right] \mathrm{His}^{+} \mathrm{Str}^{\mathrm{R}}$ \\
\hline K2.1.25 & met $B$ his ura fpk pps str & $\mathrm{F}^{-}$ & 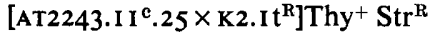 \\
\hline $\mathrm{K} 2.22$ & $\operatorname{argH}$ thr leu umg str & $\mathrm{F}^{-}$ & This paper \\
\hline $\mathrm{K} 2.22 .30$ & argH thr leu cif umg str & $\mathbf{F}^{-}$ & This paper \\
\hline $\mathrm{K} 2.2 \mathrm{I} .23 \theta$ & $\arg H$ trp thr leu ptsF pts $X$ thy A str & $\mathrm{F}^{-}$ & Laboratory stock \\
\hline $\mathrm{K} 2.2 \mathrm{I}$ & argH trp thr leu pts $X$ str & $\mathrm{F}^{-}$ & This paper \\
\hline $\mathrm{K} 2.21 .30$ & argH trp thr leu pts $X$ cif str & $\mathbf{F}^{-}$ & This paper \\
\hline $\mathrm{K} 2.21 .22 .23$ & his argH thr leu pts $X$ umg ptsF str & $\mathrm{F}^{-}$ & [KLI6.2I $\times$K2.I.22] Pps ${ }^{+} \operatorname{Str}^{\mathrm{R}}$ \\
\hline $\mathrm{K} 2.2 \mathrm{I} .22$ & his argH thr leu pts $X$ umg str & $\mathbf{F}^{-}$ & {$[\mathrm{KLI} 6 \times \mathrm{K2} .21 .22 .23] \mathrm{Fru}^{+} \mathrm{Str}^{\mathrm{R}}$} \\
\hline $\mathrm{K} 2.2 \mathrm{I} .22 .30$ & his argH thr leu ptsX umg cif str & $\mathbf{F}^{-}$ & {$[\mathrm{KLI} 6.30 \times \mathrm{K2} .21 .22 .23] \mathrm{Fru}^{+} \operatorname{Str}^{\mathrm{R}}$} \\
\hline OI I 4DFGR-W & purB umg str & $F^{-}$ & Kornberg (1972) \\
\hline $2570 \mathrm{C}$ & ptsI-3 & Hfr (KLI 6 type) & Gift from M. L. Morse \\
\hline
\end{tabular}

specifically the uptake of at least one sugar - fructose - by reacting (either directly or as glucose-6-phosphate) with a site on the inducible system that effects the uptake of fructose.

\section{METHODS}

Organisms. These were all derivatives of the KI2 strain of $E$. coli. Their relevant genotypes, and the sources from which they were derived, are listed in Table I. The abbreviations used to describe genetical markers are defined in the text, if not among those listed by Taylor \& Trotter (1972).

Organisms were grown at $37^{\circ} \mathrm{C}$ in media containing salts (Ashworth \& Kornberg, 1966), supplemented as appropriate with the required amino acids or pyrimidines to 50 to $100 \mu \mathrm{g} / \mathrm{ml}$. The genetical methods employed were those compiled by Miller (1972).

Selection of cif mutants. Samples $(0.05$ to $0.2 \mathrm{ml})$ of cultures of $E$. coli strain $\mathrm{K2}$. It that had grown overnight on medium containing $10 \mathrm{~mm}$-fructose and the required amino acids were spread on plates containing this medium supplemented with $10 \mathrm{mM-2-deoxy-D-glucose}$ and solidified with $\mathrm{I} \cdot 5 \%(\mathrm{w} / \mathrm{v})$ agar. The plates were incubated at $37^{\circ} \mathrm{C}$ for 2 to 3 days. Colonies that grew up during that time were picked on to similar plates and grown overnight; they were replica-plated on to 'Oxoid' nutrient agar supplemented with Io $\mu \mathrm{M}$ methyl- $\alpha-\mathrm{D}-\left[{ }^{14} \mathrm{C}\right]$ glucoside and again incubated at $37^{\circ} \mathrm{C}$ until good growth had been achieved ( 15 to $20 \mathrm{~h}$ ). The colonies were then transferred to Whatman No. I filter paper, by pressing a slightly-trimmed $9 \mathrm{~cm}$ disc of that paper directly on to the surface of the agar and peeling it back gently; they were air-dried and left in contact with Kodak 'Blue Brand' X-ray film for $24 \mathrm{~h}$. Mutants that had acquired their tolerance to 2-deoxyglucose by loss of the quantitatively predominant Enzyme II for the uptake of glucose and its analogues (specified by the umg gene; Kornberg \& Smith, 1972) did not blacken 
the film; these were discarded. 2-Deoxyglucose-tolerant mutants that blackened the film (and were presumably not greatly impaired in glucose uptake) were tested further by transfer from the (fructose + 2-deoxy-D-glucose) media to plates containing $20 \mathrm{mM}$-glycerol and Io mM-2-deoxy-D-glucose. One colony that grew on the former but not the latter medium, designated DAI, was purified by repeated isolation of single colonies and was used in this work.

Uptake of labelled substrates. The uptake of radioactively-labelled substrates by cultures of bacteria growing on them was measured as previously described (Kornberg, 1972, 1973a). Samples $(0.5 \mathrm{ml})$ of the cultures growing at $37^{\circ} \mathrm{C}$ in liquid media were filtered through Millipore filters $(0.45 \mu \mathrm{m}$ pore size); the filters were washed with nitrogen-free medium (Ashworth \& Kornberg, 1966) at $25^{\circ} \mathrm{C}$ and dissolved in $5 \mathrm{ml}$ of Bray's (1960) fluid in a glass scintillation vial. Samples $(0.5 \mathrm{ml})$ were also filtered through smaller Millipore filters attached to disposable $\mathrm{I} \mathrm{ml}$ syringes: portions (0.I $\mathrm{ml}$ ) of the filtrates were added to $5 \mathrm{ml}$ of Bray's (1960) fluid in a glass scintillation vial. The radioactivity in the vials was measured with a Packard 'Tri-carb' model 3385 liquid scintillation spectrometer, a total of at least 5000 counts being recorded for each vial.

The uptake of labelled substrates by washed suspensions of bacteria was measured as previously described (Morgan \& Kornberg, 1969; Ferenci \& Kornberg, 1974).

${ }^{14} \mathrm{C}$-labelled substrates were purchased from the Radiochemical Centre, Amersham, Buckinghamshire. Other chemicals were of the highest purity readily available commercially.

\section{RESULTS AND DISCUSSION}

\section{Effect of glucose and its analogues on the utilization of other sugars}

Non-catabolizable analogues of glucose, such as 2-deoxy-D-glucose, methyl- $\alpha$-D-glucoside, or 3-deoxy-3-fluoro-D-glucose are known to inhibit the utilization, by $E$. coli, of a variety of carbon sources (McGinnis \& Paigen, 1969, 1973; Kornberg \& Smith, 1972; Kornberg, 1972, 1973 $a, b$; Miles \& Pirt, 1973). In consequence, there is a rapid cessation of growth after $2 \mathrm{mM}$-2-deoxy-D-glucose is added to cultures of $E$. coli, such as the strain K2.It (Fig. I), growing on $5 \mathrm{~mm}$-lactose, $10 \mathrm{mM}$-fructose, or $20 \mathrm{mM}$-glycerol as sole carbon source. This effect was used to select mutants that continue to grow in the presence of the toxic glucose analogues: in many instances, such mutants owe their tolerance to an impaired ability to take up these glucose derivatives and the glucose they mimic. Such mutants, which show a marked increase in their doubling time on media containing glucose as sole carbon source, and an almost total loss of methyl- $\alpha$-D-glucoside transport, are designated Umg- (from uptake of methyl glucoside). The umg gene specifying this character, ascribed to an Enzyme II of the PEP-phosphotransferase system (Kundig et al. 1964) specific for glucose and methyl- $\alpha$-glucoside, has been located at $25 \mathrm{~min}$ on the $E$. coli genome (Kornberg \& Smith, 1972). As expected from this interpretation, umg mutants of $E$. coli are not inhibited by methyl- $\alpha$-glucoside, or by other glucose analogues such as 2-deoxy-D-glucose and 3-deoxy-3-fluoro-D-glucose, in their growth on any carbon source (other than galactose, which is a special case; H. L. Kornberg and C. L. Riordan, unpublished).

Although the mutant DAI of strain K2.It was selected as able to grow on fructose in the presence of 2-deoxy-D-glucose, it differed in many properties from umg mutants. For example, although the growth of strain DAI on $10 \mathrm{mM}$-fructose was only slightly retarded by the addition of 2 mM-2-deoxy-D-glucose, $0.5 \mathrm{mM}$-methyl- $\alpha$-D-glucoside, or $0.2 \mathrm{mM}-3$ deoxy-3-fluoro-D-glucose, growth was still rapidly arrested by these agents when lactose or glycerol was the carbon source (Fig. 2). Moreover, unlike umg mutants, the mutant 


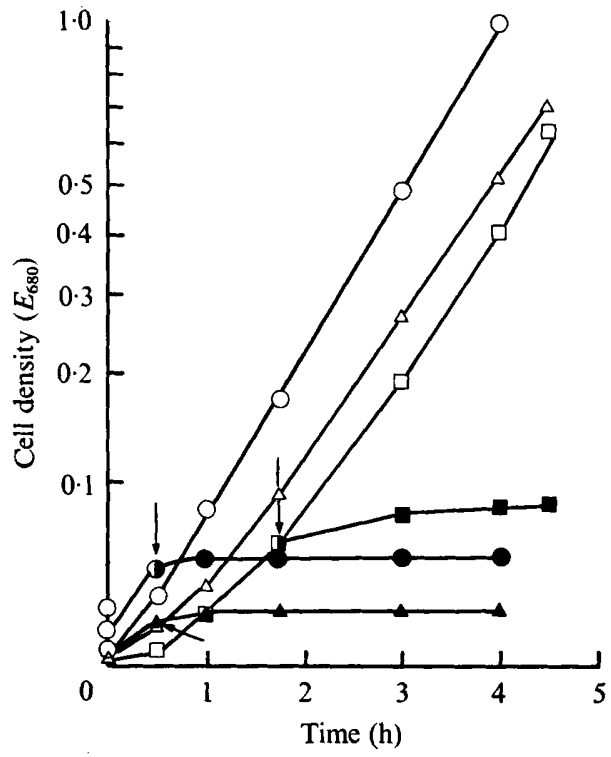

Fig. I

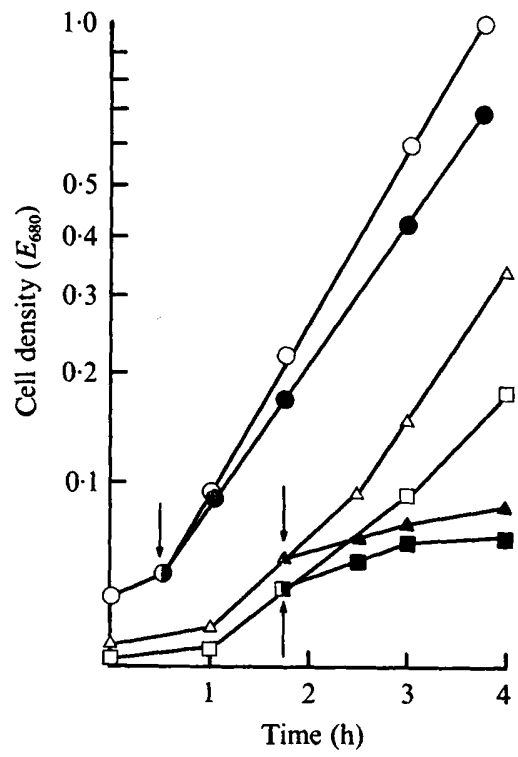

Fig. 2

Fig. I. Effect of 2 mM-2-deoxy-D-glucose on the growth of $E$. coli strain K2.It on 5 mM-lactose $(\square, \boldsymbol{\square})$, $10 \mathrm{~mm}$-fructose $(O, \bullet)$, and $20 \mathrm{~mm}$-glycerol $\Delta, \Delta)$. Duplicate flasks of cultures growing on these carbon sources were shaken at $37^{\circ} \mathrm{C} ; 2$-deoxy-D-glucose was added to one of each pair (solid symbols) at the times indicated by arrows.

Fig. 2. Effect of 2 mM-2-deoxy-D-glucose on the growth of the $E$. coli mutant DAI on 5 mM-lactose $(\square, \square), 10 \mathrm{~mm}$-fructose $(O, \Theta)$ and $20 \mathrm{~mm}$-glycerol $(\Delta, \Delta)$. Duplicate flasks of cultures growing on these carbon sources were shaken at $37^{\circ} \mathrm{C} ; 2$-deoxy-D-glucose was added to one of each pair (solid symbols) at the times indicated by arrows.

DAI grew at wild-type rates on medium containing glucose as sole carbon source, and when grown in the presence of methyl- $\alpha-\mathrm{D}-\left[{ }^{14} \mathrm{C}\right]$ glucoside it readily took up this labelled material. Thus the ability to take up glucose and its analogues had not become generally impaired, which suggests that DAI differs from its wild-type parent specifically in the manner in which glucose affects the uptake of fructose. This is supported by measurements of the rates of utilization of glucose by cultures growing on this hexose in the presence of other carbohydrates.

When fructose-grown cultures of strain K2.It were placed in media containing either $5 \mathrm{~mm}-\left[{ }^{14} \mathrm{C}\right]$ fructose $+5 \mathrm{~mm}$-unlabelled glucose, or $5 \mathrm{~mm}$-unlabelled fructose $+5 \mathrm{~mm}-\left[{ }^{14} \mathrm{C}\right]-$ glucose, over $85 \%$ of the total carbon incorporated during the growth of the organism on these sugars was derived from glucose, although the fructose-grown cells had not previously been exposed to glucose. In contrast, umg mutants derive less than $25 \%$ of their total carbon from glucose when grown upon this mixture (Kornberg, 1972, 1973 $b$; Kornberg \& Jones-Mortimer, 1975). The behaviour of strain DAI is intermediate between these extremes: as with umg mutants, glucose was no longer utilized preferentially to fructose but over $35 \%$ of the total carbon incorporated from the mixture of the two hexoses was derived from glucose (Fig. 3). When cells grown on the non-PT sugars glycerol or lactose, or on the PT sugar mannose, were allowed to grow on similar mixtures of glucose and the respective sugar, there was no significant difference between the behaviour of strain K2.It and its mutant DAI : in both, glucose virtually abolished the utilization of the sugar on 


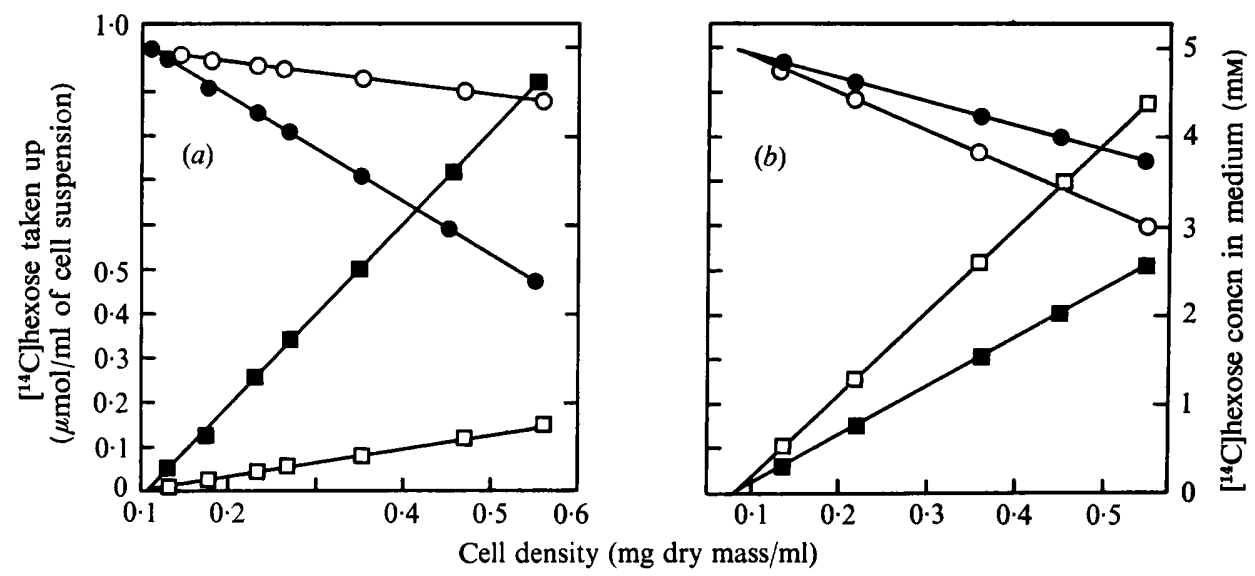

Fig. 3. Utilization of fructose and glucose by (a) E. coli strain K2.It, and (b) its mutant DAI, growing on mixtures of these sugars. Fructose-grown cells continued to grow on media containing $5 \mathrm{~mm}-\left[{ }^{14} \mathrm{C}\right]$ fructose $+5 \mathrm{~mm}$-unlabelled glucose, or $5 \mathrm{~mm}$-unlabelled fructose $+5 \mathrm{~mm}-\left[{ }^{14} \mathrm{C}\right] \mathrm{glucose}$ as carbon source. The incorporation of ${ }^{14} \mathrm{C}$ derived from fructose $(\square)$ or from glucose $(\square)$ into the growing cells, and the removal of labelled fructose $(O)$ and labelled glucose $(O)$ from the media, were measured as described in Methods.

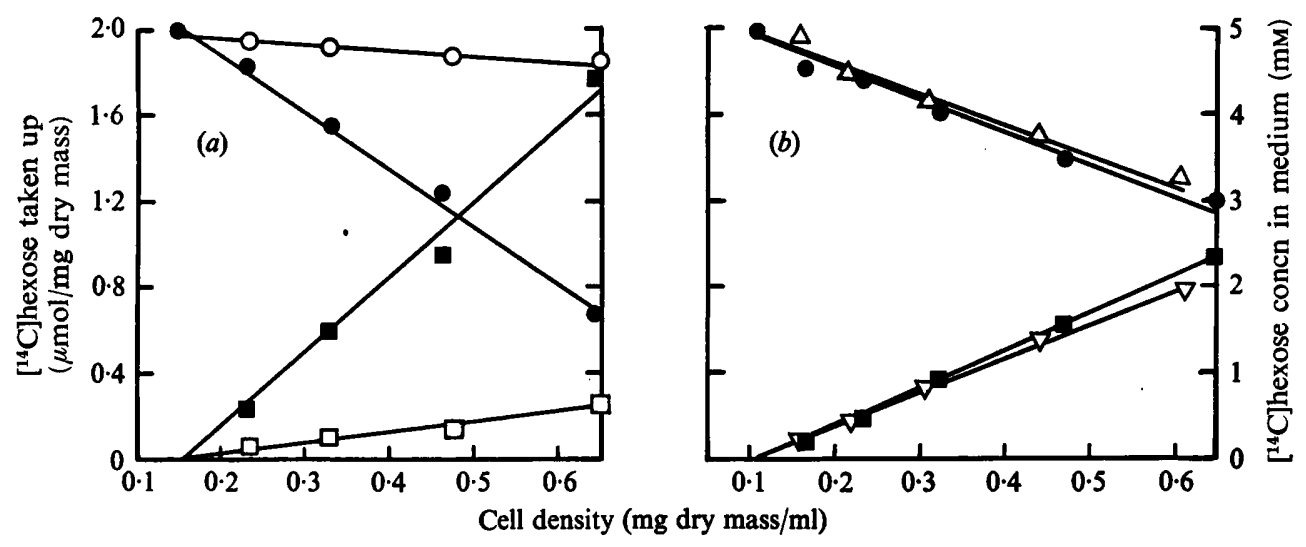

Fig. 4. Utilization of $(a)$ mannitol and glucose, and $(b)$ fructose and glucose, by a $\mathrm{Mtl}^{+}$revertant of strain DAI. Mannitol-grown cells continued to grow on media containing either (a) 5 mM$\left[{ }^{14} \mathrm{C}\right]$ mannitol $+5 \mathrm{~mm}$-glucose or $5 \mathrm{~mm}$-mannitol $+5 \mathrm{~mm}-\left[{ }^{14} \mathrm{C}\right]$ glucose, or $(b) 5 \mathrm{~mm}-\left[{ }^{14} \mathrm{C}\right]$ fructose + $5 \mathrm{~mm}$-glucose or $5 \mathrm{~mm}$-fructose $+5 \mathrm{~mm}-\left[{ }^{14} \mathrm{C}\right]$ glucose, as carbon sources. (a) The incorporation into cell materials $(\square, \square)$, and removal from the medium $(O, O)$, of mannitol (open symbols) and glucose (closed symbols). (b) The incorporation into cell materials $(\nabla, \boldsymbol{\square})$, and removal from the medium $(\triangle, \odot)$, of fructose (open symbols) and glucose (closed symbols).

which the inocula had grown. A similar experiment was done with an $\mathrm{Mtl}^{+}$revertant of strain DAI. As shown in Fig. 4, glucose strongly inhibited the utilization of mannitol but had much less effect on the utilization of fructose.

That this altered behaviour was associated with the uptake of fructose and glucose, and not with some metabolic step subsequent to the entry of these hexoses into $E$. coli, is shown in Table 2. The wild-type strain K2.It and its mutant DAI took up $\left.{ }^{14} \mathrm{C}\right]$ glucose and $\left[{ }^{14} \mathrm{C}\right]$ fructose at similar rates, which confirmed that strain DAI had not suffered any gross change in the transport of either sugar. However, whereas the presence of an excess 
Table 2. Uptake of $\left[{ }^{14} \mathrm{C}\right]$ glucose and $\left[{ }^{14} \mathrm{C}\right]$ fructose by washed cell suspensions of fructose-grown $E$. coli

Cells were harvested from the mid-exponential growth phase and suspended at $1 \cdot 4 \mathrm{mg}$ dry mass $/ \mathrm{ml}$ in nitrogen-free basal salts (Ashworth \& Kornberg, 1966). To portions ( $\mathrm{I} \mathrm{ml)} \mathrm{of} \mathrm{these} \mathrm{suspensions,}$ shaken in a water bath at $25^{\circ} \mathrm{C}$, were added water and substrates to a final volume of $2 \mathrm{ml}$. Samples $(0.2 \mathrm{ml})$ were removed $30,60,90$ and $120 \mathrm{~s}$ after addition of $\left[{ }^{14} \mathrm{C}\right]$-labelled material; these were filtered and their radioactivity was assayed as described in Methods.

\begin{tabular}{|c|c|c|c|c|}
\hline \multirow[b]{2}{*}{ Substrates } & \multicolumn{4}{|c|}{ Rates of uptake (nmol ${ }^{14} \mathrm{C} / \mathrm{min} / \mathrm{mg}$ dry mass) } \\
\hline & $\begin{array}{l}\text { K2.It } \\
\left(\text { cif }^{+}\right)\end{array}$ & $\begin{array}{l}\text { DAI } \\
\left(\text { cif }^{-}\right)\end{array}$ & $\begin{array}{c}\mathrm{K2.21.22} \\
\left(\text { cif }^{+} p t s X u m g\right)\end{array}$ & $\begin{array}{c}\mathrm{K} 2.21 .22 .30 \\
\left(\text { cif }^{-} \text {pts } X \text { umg }\right)\end{array}$ \\
\hline$\left[{ }^{14} \mathrm{C}\right]$ glucose $(0.2 \mathrm{~mm})$ & $3 \mathbf{I}$ & 29 & 2 & $\mathbf{I}$ \\
\hline$\left.{ }^{14} \mathrm{C}\right]$ fructose $(0.2 \mathrm{mM})$ & 13 & 12 & 10 & I I \\
\hline $\begin{array}{l}\left.{ }^{[14} \mathrm{C}\right] \text { fructose }(0.2 \mathrm{mM})+\text { unlabelled } \\
\text { glucose (I mM) }\end{array}$ & 5.5 & 10 & 4 & 12 \\
\hline
\end{tabular}

of unlabelled glucose reduced by over $50 \%$ the rate at which strain $\mathrm{K} 2$.It took up $\left[{ }^{14} \mathrm{C}\right]-$ fructose, it had only a slight effect on this process in strain DAI.

These results suggest that the loss of preference for glucose by the mutant DAI, which was indicated by its tolerance of usually toxic analogues (Fig. 2), by the relative rates of hexose utilization during growth on mixtures of glucose and fructose (Figs. 3 and 4), and by its behaviour in washed suspensions (Table 2), was due to an alteration in the manner in which glucose entered the cells and was associated specifically with the simultaneous uptake of fructose; no such departure from wild-type behaviour was evident when other sugars, whether taken up by the PT-system or not, were also being utilized.

\section{Location of the gene specifying the loss of catabolite inhibition exerted by glucose on the utilization of fructose (cif)}

The finding that, in contrast to wild-type strains, the mutant DAI took up and incorporated labelled fructose well although unlabelled glucose was also present, formed the basis of a method for detecting the presence of this lesion in recombinants and transductants derived from strain DAI. Three types of transductant were selected after infection of suitable recipients with phage PI propagated on the mutant DAI.

(i) Since the mutant DAI was tolerant of methyl- $\alpha$-D-glucoside (as well as of other glucose analogues) during growth on fructose, it was possible that the lesion was associated with the uptake system for this analogue (umg), particularly since this marker is known to be associated with a regulatory component of the PEP-phosphotransferase system that effects glucose utilization (Kornberg \& Smith, 1972) and has been implicated in glucosemediated catabolite repression (Tyler et al. 1969; Curtis \& Epstein, 1970; Bourd et al. 1974). Accordingly, the phage was used to infect the Umg- strain or I4DFGR-W which also carried the $\operatorname{purB}$ allele co-transducible with $u m g ; \mathrm{PurB}^{+} \mathrm{Umg}^{+}$transductants were selected as colonies that grew on glucose in the absence of adenine. However, none of the transductants thus obtained and tested had the DAI phenotype.

(ii) The possibility that the lesion in mutant DAI was associated with that region of the $E$. coli genome in which are located the genes specifying the Enzyme I and the $\mathrm{HPr}$ components of the PEP-phosphotransferase system (Wang, Morse \& Morse, 1969; Epstein, Jewett \& Fox, 1970) was tested by infecting the ptsI mutant $2570 \mathrm{C}$ with phage PI propagated on mutant DAI, and selecting Pts ${ }^{+}$transductants as colonies that grew on mannitol. None of the transductants thus obtained and tested had the DAI phenotype. 


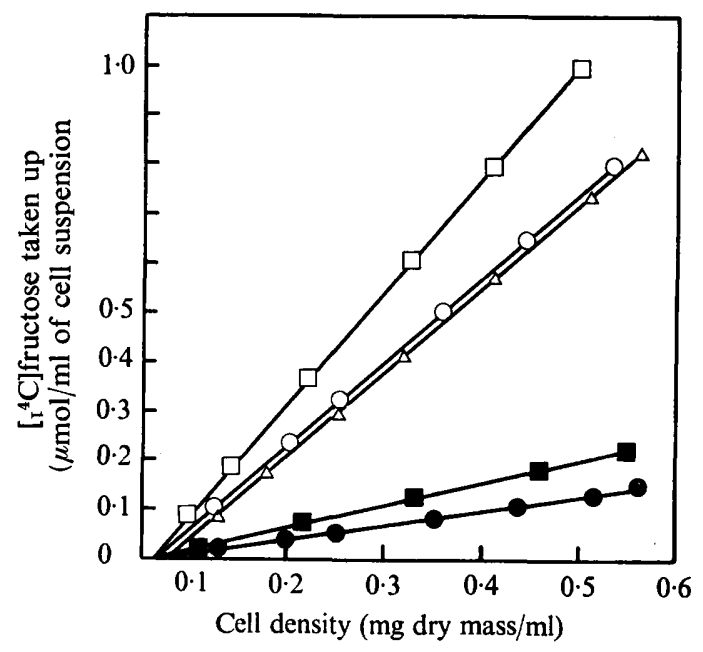

Fig. 5. Incorporation of carbon from fructose by strains of $E$. coli growing on a mixture of $5 \mathrm{mm-}$ $\left[{ }^{14} \mathrm{C}\right]$ fructose $+5 \mathrm{~mm}$-unlabelled glucose as carbon source. $\square$, Strain AT2243.I I ${ }^{\mathrm{c}}$ (parent of AT2243.I I ${ }^{\mathrm{c}} .25$ ); $\square$, its derivative DA3. O, Strain K2.It (parent of K2.I.25); $\triangle$, its mutant DAI; $O$, its derivative DA6.

(iii) Since the lesion in strain DAI became apparent only under conditions in which fructose was also being utilized, it was conceivable that it was part of, or closely associated with, the high-affinity uptake system for fructose inducibly formed by $E$. coli (Fraenkel, I968; Ferenci \& Kornberg, 197I, 1974). The gene specifying this system, ptsF, is cotransducible with the $f p k$ marker for fructose-I-phosphate kinase (Jones-Mortimer \& Kornberg, 1974). Since $f p k$ mutants do not grow on low concentrations of fructose (Ferenci \& Kornberg, 1973) although they may give rise to phenotypic revertants at higher fructose concentrations (Ferenci \& Kornberg, 1974), transductants were selected that grew rapidly on media containing $3 \mathrm{mM}$-fructose as sole carbon source: such transductants must have received the $f p k^{+}$allele, and almost certainly also the $p t s F^{+}$allele, of the phage donor strain DAI. When such transductants were selected after infection of the fpk strain AT2243. I I ${ }^{c} .25$, it was found that all the $f p k^{+}$transductants tested had acquired the phenotype of strain DAI, in so far as labelled fructose was taken up readily despite the presence of unlabelled glucose. The behaviour of one such transductant (DA3) is shown in Fig. 5. When the experiment was repeated but the phage recipient was the $f p k$ strain K2.I.25 which, like the mutant DAI, had been derived from strain K2.It, it was again found that all the $f p k^{+}$transductants tested had the phenotype of the mutant DAI. The behaviour of one such (DA6), of the donor strain DAI, and of the grandparent strains AT2243.I I ${ }^{c}$ and K2.It, are also shown in Fig. 5.

It is evident from these results that the altered phenotype of the mutant DAI is attributable to a change in an amount of genetic material so small that it can be transferred via phage Pr. Hence it is probably a change in one gene, cif, which is highly co-transducible with the genes specifying the uptake of fructose into the cell $\left(p t s F^{+}\right)$and the first metabolic step taken by the fructose-I-phosphate that thus appears inside the cell $\left(f p k^{+}\right)$. Since the character specified by the cif marker affects both the simultaneous utilization of fructose and glucose in the presence of each other by growing cells, and the uptake of these hexoses by washed cell suspensions, it is likely that the Cif- phenotype, exhibited by the mutant 


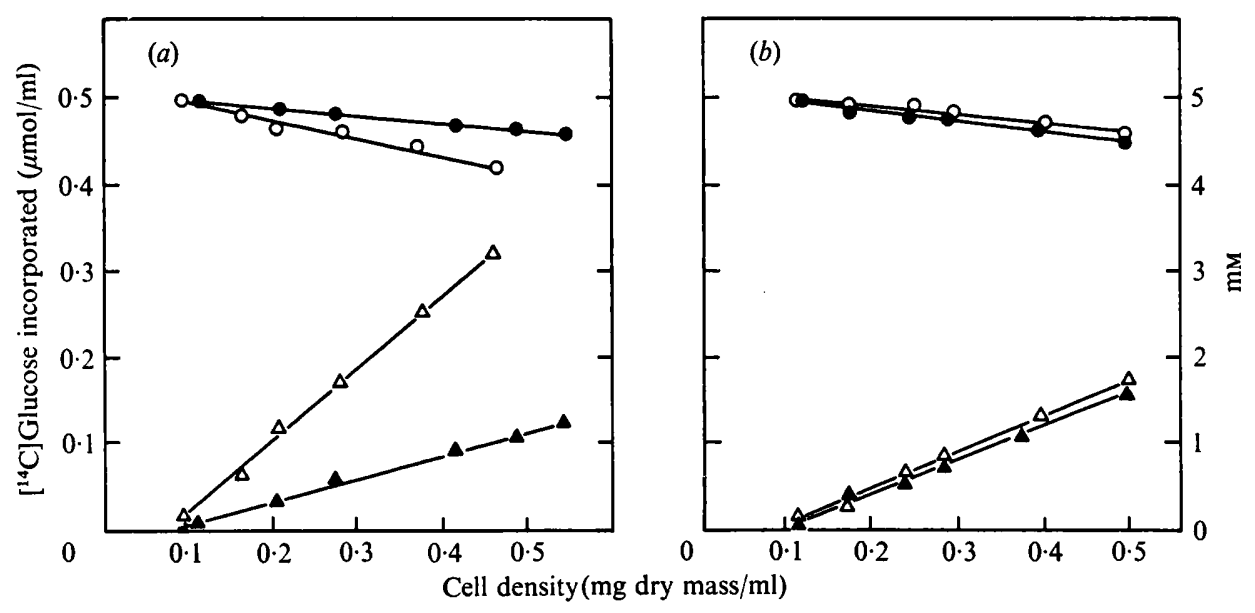

Fig. 6. Incorporation of $\left.{ }^{14} \mathrm{C}\right] \mathrm{glucose}$ by $\mathrm{cif}^{+}(\triangle)$ and cif $^{-}(\Delta)$ strains of $E$. coli that lack Umg activity. (a) Cells growing on $5 \mathrm{~mm}$-fructose $+5 \mathrm{mM}-\left[{ }^{4} \mathrm{C}\right]$ glucose; (b) cells growing on $5 \mathrm{~mm}-$ mannitol $+5 \mathrm{~mm}-\left[{ }^{14} \mathrm{C}\right]$ glucose. The removal of $\left[{ }^{14} \mathrm{C}\right]$ glucose from the growth media by $c i f^{+}(\mathrm{O})$ and cif $^{-}(\mathbf{0})$, cells is indicated.

DAI and the transductants derived from it, denotes an alteration in a glucose-specific component of the fructose-uptake system specified by $p t s F^{+}$.

\section{$A$ third route of entry of glucose into $E$. coli}

There are two major routes for the entry of glucose into the $\mathrm{K} 2$ strain of $E$. coli. The wild-type organism, and the pps mutant K2.It derived from it, double every hour when shaken at $37^{\circ} \mathrm{C}$ in media containing basal salts and Io mM-glucose. Mutants lacking the Enzyme II component of the PT-system that specifies the uptake of methyl- $\alpha-\mathrm{D}$-glucose (umg) still grow on glucose but take about $3 \mathrm{~h}$ to double; the rate at which such cells take up labelled glucose during growth on glycerol plus [ $\left.{ }^{14} \mathrm{C}\right]$ glucose is $27 \%$ of the rate at which the umg $^{+}$strain K2.It incorporates that isotope under these conditions (Kornberg \& Jones-Mortimer, 1975). This lower rate of glucose utilization is reduced still further by a mutation pts $X$, that also affects the utilization of glucosamine and mannose (Epstein \& Curtis, 1972; W. Epstein, personal communication) and the utilization of fructose at high concentrations (Ferenci \& Kornberg, 1974; Jones-Mortimer \& Kornberg, 1974). Derivatives of strain K2.It that lack both the activities specified by umg and pts $X$ require over $18 \mathrm{~h}$ to double on glucose growth medium, and, during growth on glycerol plus $\left[{ }^{14} \mathrm{C}\right]$ glucose, incorporate $\left[{ }^{14} \mathrm{C}\right]$ glucose at only $4 \%$ of the rate observed with wild-type cells (Kornberg \& Jones-Mortimer, 1975).

Since means were available for the genetic transfer of the cif marker to suitable recipients, the possibility could be tested that some glucose, not taken up via the Umg and PtsX systems, might enter cells via the fructose uptake system(s). Transduction of the cif marker from the mutant DAI into the Hfr strain KLI6.25 ( $f p k$ ) gave a strain KLI6.30 ( $f p k^{+}$cif) that transferred its genome in the direction $O-t h y$-[cif, fpk, ptsF]-his-pts $X-\ldots$ and was thus well suited to the construction of appropriate recombinants by interrupted conjugation. When this donor strain was crossed with the recipient $\mathrm{K} 2.2 \mathrm{I} .23 \theta\left(\mathrm{F}^{-}\right.$, pts $F$ pts $X$ thy $A$ str $)$, recombinants (K2.2I.30) could be readily obtained after I5 min incubation that grew on 3 mM-fructose $\left(p t s F^{+}\right)$in the absence of thymine $\left(t h y^{+}\right)$but did not grow readily on either 
glucosamine or mannose $\left(p t s X^{-}\right)$. Similar recombinants (K2.2I) were obtained from a cross of the grandparent Hfr strain KLI6 $\left(c i f^{+}\right)$with $\mathrm{K} 2.2 \mathrm{r} .23 \theta$. Both the $c i f^{+} p t s X^{-}$and cif $f^{-} p t s X^{-}$strains grew readily on mixtures of fructose and glucose. When one of these hexoses was supplied labelled with ${ }^{14} \mathrm{C}$ in the presence of the other, which was unlabelled, the results obtained did not differ significantly from those obtained with strains K2.It and DAI: the absence of the PtsX system had thus not affected the expression of the Cif character.

A similar conclusion can be drawn from experiments with $\mathrm{Umg}^{-}$strains. Such strains, that were $p t s X^{+}$, were readily constructed by transduction of the $f p k^{+}$allele from either donor strain K2.It $\left(c i f^{+}\right)$or DAI (cif-) into a recipient K2.22.25 (umg fpk). As expected, these Umg- strains took up much less $\left[{ }^{14} \mathrm{C}\right]$ glucose than did wild-type strains when growing on this hexose in the presence of another, unlabelled, substrate (Fig. 6). No difference was observed in the amounts of $\left[{ }^{14} \mathrm{C}\right]$ glucose taken up by the $c i f^{+}$and the $c i f^{-}$strains when mannitol was that unlabelled substrate, or (not shown in Fig. 6) when glycerol or lactose were the unlabelled substrates. However, in the presence of fructose, the $c i f^{+} u m g^{-}$ strain incorporated $0.8 \mu \mathrm{mol}$ glucose/increase in cell mass of $\mathrm{I} \mathrm{mg,} \mathrm{whereas} \mathrm{the} \mathrm{cif-} \mathrm{umg-}$ transductant took up only $0.26 \mu \mathrm{mol}$ under these conditions. This suggested that the induction of the PtsF system for fructose uptake had opened up a route (albeit a quantitatively minor one) for the uptake of glucose in $c i f^{+}$organisms, but this did not occur in cif $^{-}$cells.

Qualitatively similar results were obtained with mutants in which both the PtsX and the Umg systems for glucose uptake were impaired. During growth on $5 \mathrm{~mm}$-fructose + $2.5 \mathrm{mM}-\left[{ }^{14} \mathrm{C}\right] g l u c o s e$, the $c i f^{+}$pts $X$ umg mutant $\mathrm{K} 2.21 .22$ incorporated $0.3 \mathrm{I} \mu \mathrm{mol}$ isotope/ increase in cell mass of $\mathrm{I} \mathrm{mg}$, whereas during growth on $10 \mathrm{mM}$-glycerol $+2.5 \mathrm{mM}-\left[{ }^{14} \mathrm{C}\right]-$ glucose only $0.18 \mu \mathrm{mol}{ }^{14} \mathrm{C}$ was incorporated. In contrast, the otherwise isogenic but $c i f^{-}$ mutant $\mathrm{K} 2.2 \mathrm{I} .22 .30$ incorporated $0.2 \mu \mathrm{mol}\left[{ }^{14} \mathrm{C}\right]$ glucose during growth on this labelled hexose with either fructose or glycerol, unlabelled, as the other carbon source. This difference in the uptake of $\left[{ }^{14} \mathrm{C}\right] \mathrm{glucose}$ is shown also by fructose-grown suspensions of the $c i f^{+}$and cif $^{-}$mutants (Table 2). The cif $^{+}$mutant took up glucose at twice the rate of the $c i f^{-}$cells; unlabelled glucose competed for entry with $\left[{ }^{14} \mathrm{C}\right]$ fructose in the former but not the latter cells. Since no differences were apparent in the rates of $\left[{ }^{14} \mathrm{C}\right]$ fructose uptake per se, it is likely that these differences reflect the ability of the fructose-specific Enzyme II, specified by $p t s F$, to react also with, and to a minor extent translocate, glucose.

\section{Inducer exclusion}

Apart from the inhibition that glucose exerts over the continued utilization of fructose by cells grown on fructose, and which is largely overcome by the cif mutation, glucose is known to inhibit the induction of enzymes of fructose utilization by cells exposed simultaneously to both these hexoses. The results illustrated in Fig. 7, obtained with the otherwise isogenic pts $X$ strains K2.2I $\left(c^{-} f^{+}\right)$and K2.2I.30 (cif-), show that the change to cif $^{-}$ overcomes this effect of glucose also. They strengthen the view (Adhya \& Echols, 1966; Lengeler, 1966) that the failure to induce the enzymes of fructose utilization if glucose is also present is due, at least in part, to the inability of fructose sufficiently to enter the cells under these conditions.

\section{The mechanism of glucose-fructose interaction}

The observation (Kornberg, 1972) that the change from umg ${ }^{+}$to $u m g^{-}$also abolished the utilization of glucose preferentially to fructose indicates that in wild-type organisms, either glucose and fructose compete for some common component of the PEP-phospho- 


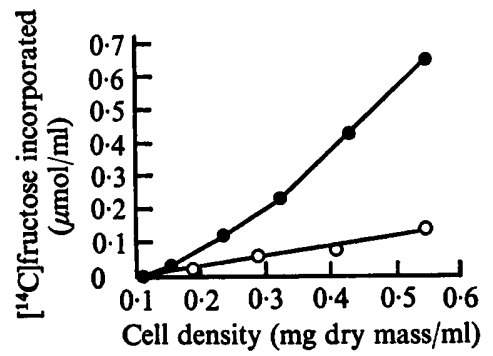

Fig. 7. Incorporation of $\left[{ }^{14} \mathrm{C}\right]$ fructose by glucose-grown $c i f^{+}(O)$ and $c i f^{-}(\bullet)$ cells continuing to grow on $5 \mathrm{~mm}$-glucose $+5 \mathrm{~mm}-\left[{ }^{14} \mathrm{C}\right]$ fructose as carbon sources.

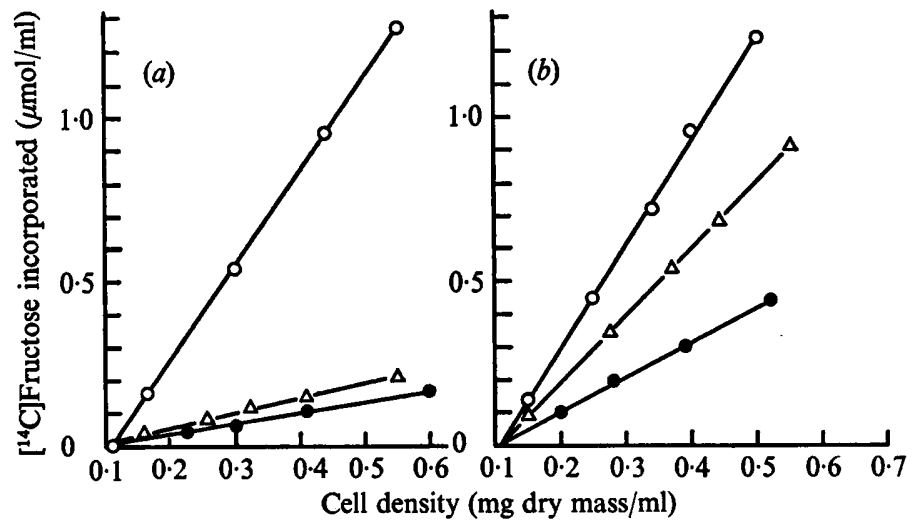

Fig. 8. Effect of glucose and glucose-6-phosphate on the incorporation of $\left[{ }^{14} \mathrm{C}\right]$ fructose by growing cif $^{+}$and cif ${ }^{-}$cells. (a) The incorporation of $\left[{ }^{14} \mathrm{C}\right]$ fructose by $c i f^{+}$cells growing on (O) $5 \mathrm{~mm}-$ fructose alone, or in the presence of $(\triangle) 5 \mathrm{mm-glucose}$ or $(\bullet) 5 \mathrm{~mm}$-glucose-6-phosphate. (b) The data obtained with cif $^{-}$cells under the same conditions.

transferase system, or the inhibition of uptake of fructose is exerted not by glucose itself but by the glucose-6-phosphate formed by the action of the Umg system. There are several lines of evidence that favour this latter explanation. For example, metabolic mutations that restrict the catabolism of glucose-6-phosphate (such as impairment of phosphoglucose isomerase and glucose-6-phosphate dehydrogenase activities) increase the degree of inhibition of fructose uptake exerted by glucose, and glucose-6-phosphate inhibits the utilization of fructose by umg mutants in which glucose is no longer effective (Kornberg, 1972). Furthermore, the accumulation of methyl- $\alpha$-D-glucoside-6-phosphate by fructosegrown wild-type cells profoundly inhibits their ability to take up [ $\left.{ }^{14} \mathrm{C}\right]$ fructose, but this ability is regained in full when the accumulated phosphate ester is washed out of the cells (Kornberg, 1973a).

Since the inhibitory effect of glucose on fructose uptake was largely overcome by mutation at the locus specified by cif, despite the unimpaired activity of the Umg system, it is possible that it is not glucose per se but glucose-6-phosphate that interacts with fructose (or fructose-I-phosphate). This conclusion receives some support from the experiment shown in Fig. 8. The incorporation of $\left[{ }^{14} \mathrm{C}\right]$ fructose by cif $p t s X$ cells growing on $5 \mathrm{~mm}$-fructose $(3.2 \mu \mathrm{mol} /$ increase in cell mass of $\mathrm{I} \mathrm{mg})$ is not significantly different from that of $c i f^{+} p t s X$ cells under the same circumstances $(2.9 \mu \mathrm{mol} /$ increase in cell mass of $\mathrm{I} \mathrm{mg}$ ). The presence of $5 \mathrm{~mm}$-unlabelled glucose reduced this rate of fructose utilization 
to $0.5 \mu \mathrm{mol} / \mathrm{mg}$ increase in $c i f^{+}$cells, but by only a small amount (to $2 \mu \mathrm{mol} / \mathrm{mg}$ increase) in $c i f^{-}$cells. Unlabelled glucose-6-phosphate produced an even greater effect in $c i f^{+}$cells: fructose utilization was reduced to $0.35 \mu \mathrm{mol} / \mathrm{mg}$ increase, which is only I $2 \%$ of the rate observed during growth on fructose as sole carbon source. However, although the utilization of fructose by the $c f^{-}$mutant was also affected by the presence of unlabelled glucose-6-phosphate, the rate of $\left[{ }^{14} \mathrm{C}\right]$ fructose incorporation observed $(\mathrm{I} \cdot 04 \mu \mathrm{mol} / \mathrm{mg}$ increase) was about three times greater than that observed with $\mathrm{cif}^{+}$cells. The simultaneous (albeit only partial) relief that the $c i f^{-}$mutation produces on the inhibition of fructose utilization by glucose and glucose-6-phosphate emphasizes the interrelationship of these two events. Since glucose-6-phosphate is known also to inhibit fructose-I-phosphate kinase activity, the effect of the high concentrations of glucose-6-phosphate added to the cells, which is illustrated in Fig. 8, may be exaggerated in this experiment: elucidation of its mechanism will require study with the purified membrane proteins specified by the cif alleles.

We thank Mr J. W. Keyte for technical assistance, Drs M. C. Jones-Mortimer, B. Low, M. L. Morse, R. H. Pritchard and A. L. Taylor for gifts of E. coli strains, The British Council for the award to D.A. of a Queen's Scholarship, and The Science Research Council for support under grant $\mathrm{B} / \mathrm{SR} / 72462$.

\section{REFERENCES}

AdHYA, S. \& Echols, H. (1966). Glucose effect and the galactose enzymes of Escherichia coli: correlation between glucose inhibition of induction and inducer transport. Journal of Bacteriology 92, 601-608.

Asensio, C., Avigad, G. \& Horecker, B. L. (1963). Preferential galactose utilization in a mutant strain of E. coli. Archives of Biochemistry and Biophysics 103, 299-309.

AshworTh, J. M. \& KorNBerg, H. L. (I966). The anaplerotic fixation of carbon dioxide by Escherichia coli. Proceedings of the Royal Society B 165, 179-188.

BonifACE, J. \& KoCH, A. L. (1967). The interaction between permeases as a tool to find their relationship on the membrane. Biochimica et biophysica acta $\mathbf{3 5}, 757-770$.

Bourd, G. I., Erlagleva, R. S., Bolshakova, T. N. \& Gershanovitch, V. N. (1974). Dissociation of systems of transport and phosphorylation of $\alpha$-methylglucoside by a mutant of Escherichia coli KI2 resistant to glucose catabolite repression. Doklady Akademii nauk SSSR 215, 1243-1246.

BrAY, G. A. (1960). A simple efficient liquid scintillator for counting aqueous solutions in a liquid scintillation counter. Analytical Biochemistry I, 279-285.

Brice, C. B. \& KoRNBERG, H. L. (1967). Location of a gene specifying phosphopyruvate synthase activity on the genome of Escherichia coli KI2. Proceedings of the Royal Society B 168, 28I-292.

Curtis, S. J. \& Epstein, W. (1970). Two constitutive P-HPr: glucose phosphotransferases in Escherichia coli K1 2. Federation Proceedings 30, I 123.

EPSTEIN, W. \& CURTIS, S. J. (1972). Genetics of the phosphotransferase system. In Role of Membranes in Secretory Processes, pp. 98-1 12 . Edited by C. L. Bolis. Amsterdam: North-Holland.

EPSTEIN, W., JeWETT, S. \& Fox, C. F. (1970). Isolation and mapping of phosphotransferase mutants in Escherichia coli. Journal of Bacteriology 104, 793-797.

Ferenci, T. \& Kornberg, H. L. (1971). Pathway of fructose utilization by Escherichia coli. FEBS Letters 13, $127-130$.

Ferenci, T. \& Kornberg, H. L. (1973). The utilization of fructose by Escherichia coli. Properties of a mutant defective in fructose I-phosphate kinase activity. Biochemical Journal 132, 34I-347.

FerenCI, T. \& KorNBerg, H. L. (1974). The role of phosphotransferase-mediated syntheses of fructose 1-phosphate and fructose 6-phosphate in the growth of Escherichia coli on fructose. Proceedings of the Royal Society B 187, 105-I 19.

FRAENKEL, D. G. (1968). The phosphoenolpyruvate-initiated pathway of fructose metabolism in Escherichia coli. Journal of Biological Chemistry 243, 6458-6463.

JONES-MORTIMER, M. C. \& KorNBERG, H. L. (1974). Genetical analysis of fructose utilization by Escherichia coli. Proceedings of the Royal Society B 187, $12 \mathrm{I}-\mathrm{I} 3 \mathrm{I}$. 
KePES, A. (1960). Etudes cinétiques sur la galactoside-perméase d'Escherichia coli. Biochimica et biophysica acta 40, 70-84.

Kessler, D. P. \& Rickenberg, H. V. (1963). The competitive inhibition of $\alpha$-methylglucoside uptake in Escherichia coli. Biochemical and Biophysical Research Communications 10, 482-487.

KосH, A. L. (1964). The role of permease in transport. Biochimica et biophysica acta 79, 177-200.

KoRnBerg, H. L. (1972). Nature and regulation of hexose uptake by Escherichia coli. In The Molecular Basis of Biological Transport, pp. 157-180. Edited by J. F. Woessner, Jun. and F. Huijing. New York and London: Academic Press.

Kornberg, H. L. (1973a). Fine control of sugar uptake by Escherichia coli. Symposia of the Society of Experimental Biology 27, 175-193.

KornberG, H. L. (1973b). The Leeuwenhoek Lecture. Carbohydrate transport by micro-organisms. Proceedings of the Royal Society B 183, 105-I23.

Kornberg, H. L. \& Jones-Mortimer, M. C. (1975). Pts $X$ : A gene involved in the uptake of glucose and of fructose by Escherichia coli. FEBS Letters 51, I-4.

KornBERG, H. L. \& SMITH, J. (1972). Genetic control of glucose uptake by Escherichia coli. FEBS Letters 20, 270-272.

Kundig, W., Ghosh, S. \& Roseman, S. (1964). Phosphate bound to histidine in a protein as an intermediate in a novel phosphotransferase system. Proceedings of the National Academy of Sciences of the United States of America 52, 1064-1074.

LENGELER, J. (1966). Untersuchungen zum Glukose-Effekt bei der Synthese der Galaktose-Enzyme von Escherichia coli. Zeitschrift für Vererbungslehre 98, 203-229.

McGinnis, J. F. \& Paigen, K. (1969). Catabolite inhibition: a general phenomenon in the control of carbohydrate utilization. Journal of Bacteriology roo, 902-913.

McGinnis, J. F. \& Paigen, K. (I973). Site of catabolite inhibition of carbohydrate metabolism. Journal of Bacteriology 114, 885-887.

Miles, R. J. \& PIRT, S. J. (1973). Inhibition by 3-deoxy-3-fluoro-D-glucose of the utilization of lactose and other carbon sources by Escherichia coli. Journal of General Microbiology 76, 305-318.

Miller, J. H. (1972). Experiments in Molecular Genetics. Cold Spring Harbor Laboratory.

Morgan, M. J. \& KornberG, H. L. (1969). Regulation of sugar accumulation by Escherichia coli. FEBS Letters 3, 53-56.

TAYLoR, A. L. \& TrotTer, C. D. (1972). Linkage map of Escherichia coli strain KI 2. Bacteriological Reviews 36, 504-524.

Tyler, B., Wishnow, R., Loomis, W. F. \& Magasanik, B. (1969). Catabolite repression gene of Escherichia coli. Journal of Bacteriology Ioo, 809-8I6.

WANG, R. J., Morse, H. G. \& MorSE, M. L. (1969). Carbohydrate accumulation and metabolism in Escherichia coli: the close linkage and chromosomal location of ctr mutations. Journal of Bacteriology 98, 605-6Io.

WINKLER, H. H. \& WILSON, T. H. (1967). Inhibition of $\beta$-galactoside transport by substrates of the glucose transport system in Escherichia coli. Biochimica et biophysica acta 135, 1030-105I. 